IJMS 2018 vol. 5 (2): 79 - 83

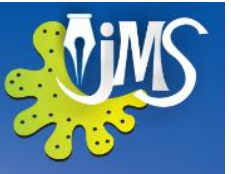

International Journal of Multidisciplinary Studies (IJMS)

Volume 5, Issue 2, 2018

\title{
Prevalence and Risk Factors of Upper Back Pain among Heavy Vehicle Drivers in Galle District, Southern Province, Sri Lanka
}

Gajanayaka H.H. * and Jayakody J.A.N.A.

School of physiotherapy, International Institute of Health Sciences

\begin{abstract}
Musculoskeletal Disorders (MSD) due to occupational factors is more common in drivers at present. Various factors such as driving for long hours, driving seat position, angles and posture can affect the drivers to get Musculoskeletal Disorders. Professional drivers are a high-risk group for musculoskeletal disorders involving the spine, shoulder, back, neck, knee and pains in upper and lower extremities. Objectives of this research were to assess the prevalence and risk factors of upper back pain among heavy vehicle drivers in Galle district. A descriptive cross-sectional study was done on a conveniently selected sample of 80 heavy vehicle drivers in Galle district using a self-administered questionnaire. $77.8 \%$ of the drivers drive for more than 6 hours per day. 63\% of them had numbness in their neck and shoulder area. 54\% of them stated that the pain affects their carrier. $62 \%$ out of them stated that they get upper back pain while driving. 47 participants have stated that they get upper back pain mostly on the following day after a drive. Majority of them (64\%) do not keep any back support and they lean to the seat while driving. Only 32\% of the participants had sought medications for their conditions. Majority of them have used home remedies for their musculoskeletal pain without seeking any medical advice. Among heavy vehicle drivers, upper back pain is one of the most commonly identified Musculoskeletal Disorder. Driving for long hours and the wrong sitting posture are the most common risk factors for upper back pain among heavy vehicle drivers.
\end{abstract}

KEYWORDs: Muscular-Skeletal Disorders, Risk Factors, Upper Back Pain, Heavy Vehicle Drivers, Galle District

Corresponding author: Gajanayaka H.H ., Email: hiru.gajanayake@gmail.com 


\section{INTRODUCTION}

Driving is a profession that is vital to the economy of every country. In Sri Lanka, there are so many people who do driving as their main occupation. These people include the drivers who work in public transport services, those who work in the construction sites and those who transport goods inside the country.

Professional drivers are a high-risk group for musculoskeletal disorders involving the spine, shoulder, back, neck, knee and pains in upper and lower extremities. They include conditions such as tendinitis, fibromyalgia, osteoarthritis, rheumatoid arthritis and carpal tunnel syndrome. These disorders are extremely common in these days and the risk of developing these Musculoskeletal Disorders increases with the age. Severity can be varied (Health line, 2016) Work-related musculoskeletal disorders are defined as impairments of the musculoskeletal system aggravated primarily by the work itself or by the environment in which the work is performed.

\subsection{Background of the study}

Prevalence of these musculoskeletal diseases among the drivers is a common issue at present. Among them, heavy vehicle drivers face immense problems which related to their musculoskeletal conditions. (Abledu, Offei and Abledu, 2014).

Various factors like driver's seat, control mechanisms, vibration generated and long time sitting can be count as some factors which contribute for the drivers to develop musculoskeletal disorders in their extremities. Mostly after a long stay of rest, performance of mechanically demanding activities collapse due to tightening of the muscles of the back area and neck because of the deficiency of attentiveness. (Muhammad Wajahat, Fahad and Hafiz Sheraz, 2016)

\section{METHODOLOGY}

The descriptive cross-sectional study was followed to do this research and Quantitative research was carried out with a questionnaire on drivers. Drivers in Galle district which belongs to several areas were used as the population for this research. These drivers include bus drivers, lorry drivers and JCB drivers who are concerned as heavy vehicle drivers. Convenient sampling was used by taking all the drivers which the researcher can access without any randomization.

A convenience based sample of 100 was taken, from several areas in Galle district as the sample size for this research. Through an administered questionnaire on face to face basis, data collected by researcher herself at the villages.

\section{RESULTS \& DISCUSSION}

$77.8 \%$ of the drivers drive for more than 6 hours per day. $63 \%$ of them had numbness in their neck and shoulder area. 54\% of them stated that the pain affects their carrier. $62 \%$ out of them stated that they get upper back pain while driving. $47 \%$ of participants have stated that they get upper back pain mostly on the following day after a drive. Majority of them (64\%) do not keep any back support and they lean to the seat while driving. Only $32 \%$ of the participants had sought medications for their conditions. Majority of them have used home remedies for their musculoskeletal pain without seeking any medical advice. 


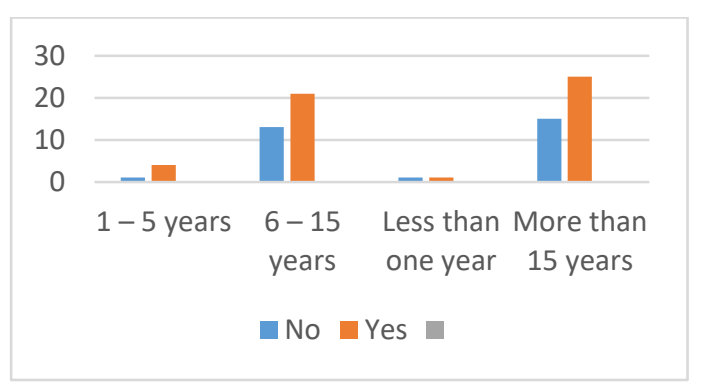

Figure 1: Neck pain Associated with the Duration of Work

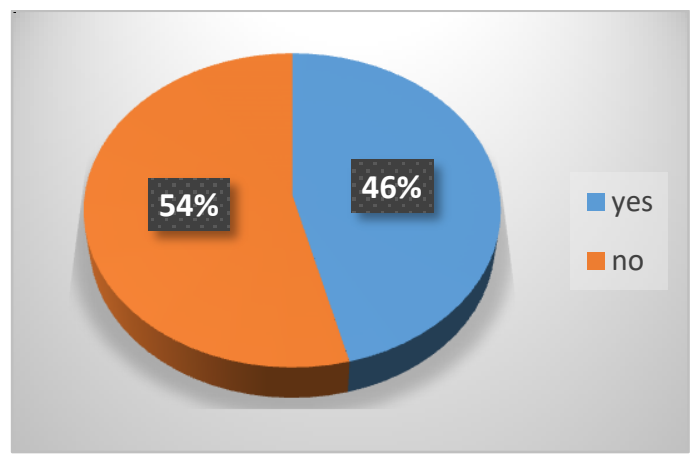

Figure 2: Effect of Neck Pain on Driving

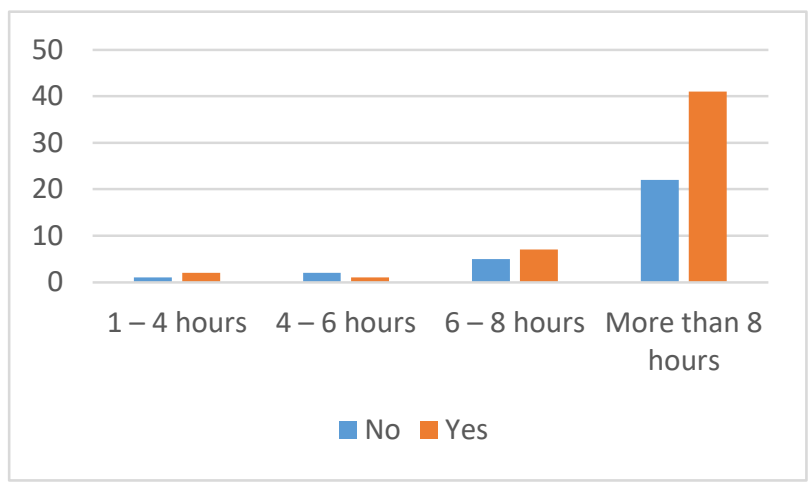

Figure 3: Neck pain associated with Working hours per week

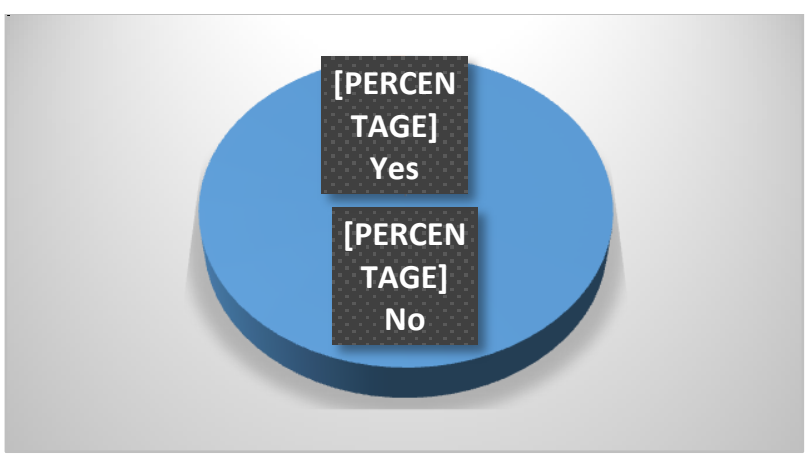

Figure 4: Recommendation from a Doctor for Exercises to relieve the pain

According to a cross-sectional study which was done to determine the risk factors associated with complaint of low back pain it states that a high prevalence of Malaysian commercial vehicle drivers (60.4\%) has presented with low back pain. A research which has been conducted to determine the prevalence and predictors of work-related musculoskeletal disorders (WMSDs) among a sample of commercial minibus drivers in the Accra Metropolis of Ghana

has stated that $78.4 \%$ of the drivers have work-related musculoskeletal disorders. According to the research conducted in Galle district, $54 \%$ of the drivers have stated that the back pain affects their occupation. $77.8 \%$ of the drivers drive for more than 6 hours per day and 63\% of them had numbness in their neck and shoulder area. Research will be carried out to determine the relationship between the number of driving hours and the prevalence of muscular skeletal disorders in the future.

\section{CONCLUSION}

Heavy vehicle drivers are more prone to get MSD. Among heavy vehicle drivers, upper back pain is one of the most commonly identified MSD. Driving for long hours and the wrong sitting posture are the most common risk factors for upper back pain among heavy vehicle drivers. 


\section{ACKNOWLEDGMENT}

I express my sincere thanks to Dr. Kithsiri Edirisinghe to encourage me to the highest peak and to provide me the opportunity to prepare the project.

I also pay my deep sense of gratitude to Dr. Nishan Silva for all the advice he has given for me to conduct this research in a correct manner. I feel to acknowledge my indebtedness and a deep sense of gratitude the wrong sitting posture are the most common risk factors for upper back pain among heavy vehicle drivers to the guide by Mr. Nipun Anuradha Jayakody whose valuable guidance and kind supervision given to me through the course which shapes the present work as its show. I am also immensely obliged to Mr. Indika Koralegedera and Mr. Damith for giving their valuable advice throughout this project. Last but not least, my parents and my brother are also an inspiration for me. SO with due regards, I express my gratitude to them.

\section{REFERENCES}

ABLEDU, J., OFFEI, E. and ABLEDU, G. (2014). Occupational and Personal Determinants of Musculoskeletal Disorders among Urban Taxi Drivers in Ghana. [online] Hindawi. Available at: https://www.hindawi.com/journals/isrn/201 4/517259/ [Accessed 24 Sep. 2017].

ARIËNS, G., MECHELEN, W., BONGERS, P., BOUTER, L. and VAN DER WAL, G. (2000). Physical risk factors for neck pain on JSTOR. [online] Jstor.org. Available at: http://www.jstor.org/stable/40967013?seq= 1\#page_scan_tab_contents [Accessed 25 Sep. 2017].
BENSTOWE, S. (2008). Long Driving Hours and Health of Truck Drivers. [online] Available at: http://archives.njit.edu/vol01/etd/2000s/200 8/njit-etd2008-006/njit-etd2008-006.pdf [Accessed 24 Sep. 2017].

MUHAMMAD WAJAHAT, A., FAHAD, T. and HAFIZ SHERAZ, A. (2016). Jobrelated Musculoskeletal Disorders in Bus Drivers of Lahore, Pakistan. [online] Available at: https://www.ijsr.net/archive/v5i5/NOV1634 03.pdf [Accessed 24 Sep. 2017].

NAJENSON, D., SANTO, Y., MASHARAWI, Y., KATZ-LEURE, M., USHVAEV, D. and KALICHMAN, L. (2010). IMAJ | The Israel Medicine Association Journal | Volume 12, Number 1, January 2010 | Low Back Pain among Professional Bus Drivers: Ergonomic and Occupational-Psychosocial Risk Factors. [online] Ima.org.il. Available at:

https://www.ima.org.il/MedicineIMAJ/view article.aspx?aid=40 [Accessed 26 Sep. 2017].

OSUMANU, M. (2015). Prevalence of Musculoskeletal Disorders among Commercial Long Distance Bus Drivers in the Greater Accra Region, Ghana. [online] Ugspace.ug.edu.gh. Available at: http://ugspace.ug.edu.gh:8080/xmlui/handle /123456789/21776 [Accessed 27 Sep. 2017].

REHN, B., BERGDAHL, I., AHLGREN, C., FROM, C., JÄRVHOLM, B., LUNDSTRÖM, R., NILSSON, T. and SUNDELIN, G. (2002). Musculoskeletal Symptoms among Drivers of All-Terrain Vehicles. [online] Available at: http://www.sciencedirect.com/science/articl e/pii/S0022460X01942476 [Accessed 25 Sep. 2017]. 
SAMRAT, D. and GANGOPADHYAY, S. (2012). Upper body musculoskeletal disorders among professional nongovernment city bus drivers of Kolkata IEEE Conference Publication. [online] Ieeexplore.ieee.org. Available at: http://ieeexplore.ieee.org/document/629955 6/ [Accessed 25 Sep. 2017].

TAMRIN, S., YOKOYAMA, K., JALALUDIN, J. and ABDUL AZIZ, N. (2006). The association between risk factors and low back pain among commercial vehicle drivers in Peninsular Malaysia: A Preliminary result. [online] Available at: https://www.jstage.jst.go.jp/article/indhealt h/45/2/45_2_268/_pdf [Accessed 25 Sep. 2017]. 